\title{
Ocorrência de micobactérias em suínos de abate clandestino no Rio de Janeiro, Brasil
}

\section{Occurrence of mycobacteria in swine of clandestine slaughter in Rio de Janeiro, Brazil}

\author{
Walter Lilenbaum, ${ }^{\star}$ Maria Helena Feres Saad, ${ }^{\star \star}$ Orlando Marcelino Santos, ${ }^{\star \star *}$ Marlei Gomes Silva, ${ }^{\star \star \star}$ \\ Luciana Fonseca Sobral, ${ }^{\star \star \star \star}$ Leila Souza Fonseca ${ }^{\star \star \star \star \star}$
}

\begin{abstract}
Resumo
O estudo das micobactérias atípicas; em especial das que compõem o complexo Mycobaterium avium (MAC), vem crescendo em função de sua associação com diferentes tipos de patologias, principalmente em pacientes imunodeprimidos. Suínos podem atuar como reservatórios destes microrganismos e o exame destes animais em uma região específica permite avaliar a situação epidemiológica das micobacterioses na população humana e das espécies animais. Foram examinados 73 suínos abatidos no ambiente de criação, sem a devida inspeção sanitária. Isolaram-se 21 amostras, sendo sete amostras de crescimento rápido, seis pertencentes MAC e uma Mycobacterium scrofulaceum. Foram ainda identificadas 14 de micobactérias atípicas de crescimento rápido, classificadas em $M$. flavescens (4 amostras), $M$. chitae ( 3 amostras), M. peregrinum (2 amostras), $M$. fortuitum ( 2 amostras) e $M$. diernhoferi (1 amostra). Consideramos os índices de isolamento verificados bastante altos, especialmente tendo em vista que esses animais são consumidos diretamente sem qualquer espécie de fiscalização sanitária ou de tratamento prévio dos produtos. Desta forma, consideramos que os animais oriundos de abate clandestino representam importante risco de contaminação ambiental e da população humana exposta a micobactérias em geral e, especialmente, às do MAC.
\end{abstract}

Palavras-chave: micobactérias, tuberculose, suínos.

\begin{abstract}
The study of atypical mycobacteria, especially of those that compose the $M$. avium complex (MAC), is growing in function of their association with different pathologies, mainly in immunocompromised individuals. Swine can act as reservoirs of these bacteria and the exam of swine of an area allow evaluating the epidemic situation of mycobacteriosis infection in the human and animal population. Seventy-three swine slaughtered without the due sanitary inspection were examined. It was isolated 21 samples, being seven samples of fast growth, six of them belonging to the MAC and one Mycobacterium scrofulaceum. We also identified 14 fast-growing atypical mycobacteria classified in $M$. flavescens (4 samples), $M$. chitae ( 3 samples), $M$. peregrinum ( 2 samples) $M$. fortuitum ( 2 samples) and $M$. diernhoferi (1 sample). We considered the percentage of isolation quite high, especially considering that those animals are consumed without any species of sanitary inspection. This way, we considered that the animals originating from clandestine slaughtering represent important risk of environmental contamination and of the human population exposed to mycobacteria in general and especially to the MAC.
\end{abstract}

Keywords: mycobacteria, tuberculosis, swine.

\section{Introdução}

Micobactérias são bastonetes finos, álcool-ácido resistentes, curvados e resistentes a ácidos, álcalis, e à desidratação, devido principalmente à sua parede celular, que contém ceras complexas e glicolipídeos. A multiplicação em meios enriquecidos é muito lenta, com tempo de geração de 18 a 24 horas, e o isolamento a partir de amostras clínicas pode exigir quatro a seis semanas para crescer. A partir da velocidade de crescimento, catalase e produção de niacina, e pigmentação em luz ou escuro, as micobactérias são classificados como membros do complexo Mycobacterium tuberculosis (Mycobacterium tuberculosis, $M$. bovis, $M$. africanum, $M$. microtii) ou como espécies atípicas, também denominadas não-tuberculosas. Micobactérias atípicas são classificadas através de pigmentação na luz ou escuro e através da velocidade de crescimento. Várias espécies contêm muitos sorotipos, baseado na ação antigênica de diferentes lipo-

\footnotetext{
* MVD, PhD, Departamento de Microbiologia e Parasitologia, Universidade Federal Fluminense. E-mail: mipwalt@vm.uff.br

** PhD, Laboratório de Hanseníase, Fundação Oswaldo Cruz.

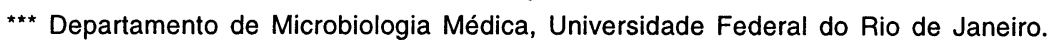

**** Bolsista Iniciação Científica.

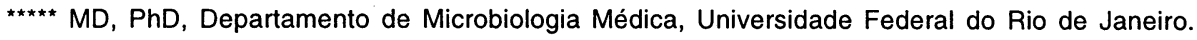


oligosacarídeos ou peptidoglicolipídeos. Atualmente a distinção destes sorotipos vem sendo facilitada pelo uso de sondas genéticas.

Micobactérias atípicas apresentam multiplicação semelhante à de outras micobactérias, com exceção das de crescimento rápido (como $M$. fortuitum). Ultimamente seu estudo, em especial das espécies $M$. avium e $M$. intracellulare, que compõem o complexo M. avium (MAC - Mycobacterium avium complex), vem crescendo em função de sua associação com diferentes tipos de patologias, principalmente em pacientes imunodeprimidos (Thoen, 1994). Os pacientes podem exibir doença das vias respiratórias semelhante à tuberculose $(M$. kansasii, M. avium-intracellulare), linfadenite cervical, especialmente em crianças ( $M$. scrofulaceum), infecções de tecidos moles e pele ( $M$. ulcerans, $M$. marinum), ou mesmo doença disseminada em pessoas infectadas com HIV, em quem o complexo $M$. avium-intracellulare é responsável por mais de $90 \%$ dos casos (Horsburgh, 1991; Saad et al., 1999). A infecção não é transmissível entre humanos, mas é adquirida de fontes ambientais, como solo e água. Animais como suínos e aves podem atuar como reservatórios destes microrganismos e, através de estudos de caracterização genotípica de amostras de $M$. avium de origem suína, comprovou-se que estas apresentam várias características genéticas em comum com amostras humanas (Bono et al., 1995, Komijn et al., 1999).

Segundo Mota et al. (1980) e Ferreira Neto et al. (1989), o exame de suínos de uma região permite avaliar a situação epidemiológica da tuberculose e das micobactérias na população humana e das espécies animais, sendo classificada como espécie reveladora da presença de micobacterioses em determinada região. Estudos epidemiológicos sobre a linfadenite micobacteriana ern suínos indicam que amostras do MAC são responsáveis pela maior parte dos casos. Segundo Thoen (1994), apesar das lesões se encontrarem usualmente restritas aos linfondos, envolvimento generalizado com variações que vão desde a presença de pequenos focos em diversos órgãos da cavidade abdominal até lesões nodulares extensas envolvendo fígado, baço e rins podem ser observadas.

O abate clandestino representa séria ameaça à saúde pública. Em 1987, uma comissão designada a quantificar o abate clandestino em nosso país (CRMV-RJ, 1987) estimou em $68,27 \%$ a quantidade de carcaças de bovinos abatidas sem a devida inspeção sanitária no estado do Rio de Janeiro, naquele ano. Aplicando-se este dado ao risco específico para a tuberculose, estimou-se que cerca de 1600 carcaças de bovinos infectadas teriam sido comercializadas, apesar de apresentar lesões compativeis com tuberculose. Para o abate de suínos, embora não haja estimativas específicas, ao se aplicar os mesmos índices constata-se que cerca de $140 \mathrm{mil}$ animais teriam sido abatidos de forma clandestina, o que representaria 700 carcaças de animais potencialmente transmissores de tuberculose sendo comercializadas naquele ano.

\section{Material e métodos}

Animais - Foram examinados 73 suínos adultos, sem raça definida, de ambos os sexos, sem sinais aparentes ou histórico de tuberculose ou outra alteração clínica digna de nota.
Os animais eram criados livremente em ambientes insalubres, em bairros populares da periferia do município do Rio de Janeiro, estando em contato direto com o solo e sendo alimentados com restos de alimentação humana. $O$ abate foi realizado no ambiente de criação, sem a devida inspeção sanitária, o que configura um abate clandestino sem o uso de técnicas que visem à melhor qualidade sanitária do produto. O destino usual das carcaças é o comércio em feiras livres do bairro e o consumo humano a fresco.

Amostras - Durante o abate foi retirada a árvore respiratória, incluindo desde a laringe até os pulmões íntegros, e levada imediatamente ao laboratório, sob refrigeração. Ao exame macroscópico das peças seguiu-se a coleta de amostras de linfonodos traqueobrônquicos craniais e médios e de fragmentos de pulmão para isolamento. Uma pequena porção de cada material $(1-5 \mathrm{~g})$ foi cortada em pequenos pedaços com uma lâmina esterilizada e triturada em um volume total de $10 \mathrm{ml}$ de tampão fosfato (PBS) em gral esterilizado, após retirada dos tecidos fibrosos e gorduras e exame da superfície dos tecidos para identificação de lesões externas. Quando possivel, os tecidos foram divididos em porções iguais e metade guardada congelada para uma análise confirmatória, porventura necessária. De todas as amostras recebidas no laboratório, foi realizada a baciloscopia corada pelo método de Ziehl-Neelsen, para avaliação da presença de bacilos álcool-ácido resistentes (BAAR). O procedimento de isolamento incluiu o seccionamento dos linfonodos, trituração em gral com areia esterilizada e descontaminação segundo o método de Petroff, que se baseia no uso de $\mathrm{NaOH}$ a $4 \%$ como elemento ativo, seguido de centrifugação e semeadura nos meios Löwenstein-Jensen e de 7H11(Difco), sempre em duplicata. Os tubos eram incubados em estufa a $37^{\circ} \mathrm{C}$, com exame semanal por até doze semanas.

Isolados - As leituras dos tubos inoculados foram realizadas semanalmente, até completar doże semanas. Uma vez constatada a presença de unidades formadoras de colônias (UFC), estas foram submetidas à coloração de Ziehı Neelsen, e aquelas caracterizadas como BAAR foram tipificadas conforme Kent e Kubica (1985). As provas bioquímicas realizadas foram a de aril-sulfatase em três dias, produção de niacina, redução do nitrato, incorporação de ferro, fermentação de carboidratos (galactose, arabinose, inositol, manitol), produção de pigmento, catalase a $68^{\circ} \mathrm{C}$, hidrólise do tween 80 , redução do telurito e urease. As amostras identificadas como MAC foram ainda avaliadas quanto à presença da seqüência de inserção IS 1245, capaz de diferenciar entre amostras de $M$. avium e de $M$. intracellulare. Esta avaliação foi realizada pela amplificação por PCR (polymerase chain reaction) de uma seqüência interna de IS $1245 \mathrm{com} 427$ pares de bases, conforme Saad et al. (1999).

\section{Resultados e discussão}

Dentre os 73 animais abatidos, em nenhum deles se observaram sinais macroscópicos sugestivos de tuberculose ou quaisquer outras lesões na árvore respiratória. Dos 146 tubos semeados, observou-se crescimento sugestivo de micobactérias em $36(49,3 \%)$, embora em apenas 21 tubos $(28,8 \%)$ tenha sido possível confirmar o isolamento de micobactérias. Após a realização das provas bioquímicas de identificação, verificou-se que, das 21 amostras obtidas, 14 eram de micobactérias atípicas de crescimento rápido, clas- 
sificadas em M. flavescens (4 amostras), M. chitae (3 amostras), $M$. peregrinum (2 amostras) $M$. fortuitum (2 amostras) e M. diernhoferi (1 amostra). Outras duas amostras de crescimento rápido não foram identificadas pelas provas utilizadas de identificação bioquímica (Tabela 1). A IS 1245 tem sido relatada como exclusiva de M.avium subespécies avium, sylvaticum e paratuberculosis, constituindo-se numa ferramenta útil para diferenciar estes isolados dos de $M$. intracellulare (Saad et al., 1999). Desta forma, consideramos que a utilização desta ferramenta de biologia molecular permitiu neste estudo, uma classificação confiável e bastante específica das amostras de MAC.

Tabela 1: Isolamentos de micobactérias a partir de linfonodos de suínos de abate clandestino no Rio de Janeiro, Brasil.

\begin{tabular}{cc}
\multicolumn{1}{c}{ ITENS } & NUMMERO \\
\hline Animais examinados & 73 \\
Tubos com crescimento & 36 \\
Micobactérias confirmadas & 21 \\
. Crescimento lento & 7 \\
M. avium (MAC) & 6 \\
M. scrofulaceum & 1 \\
. Crescimento rápido & 14 \\
M. flavescens & 4 \\
M. chitae & 3 \\
M. peregrinum & 2 \\
M. fortuitum & 2 \\
M. diernhoferi & 1 \\
Não identificadas & 2 \\
\hline
\end{tabular}

Pestana de Castro et al. (1978) relataram que, apesar de serem usualmente consideradas como saprófitas, amostras de $M$. flavescens e de $M$. fortuitum foram identificadas determinando infecções em suínos. Amostras de $M$. fortuitum já foram isoladas de abscessos humanos e podem causar adenites e mais raramente infecções pulmonares e doença pulmonar crônica. Em pacientes imunodeprimidos já foi isolada em doença micobacteriana disseminada. Segundo Palhano Jir. et al. (1986), M. fortuitum é a micobactéria atípica mais freqüentemente isolada de pacientes humanos sadios e tuberculosos no Brasil, tendo sido relatada também por Fonseca \& Gontijo Filho (1978). M. scrofulaceum já foi descrita determinando infecção pulmonar no homem (Andrade et al., 1986) e, assim como as demais infecções determinadas por micobactérias atípicas, acomete usualmente indivíduos imunodeprimidos e/ou com doença pulmonar prévia.

Foram ainda isoladas e identificadas sete amostras de crescimento rápido, seis confirmadas como pertencentes ao MAC e uma delas identificada como sendo da espécie Mycobacterium scrofulaceum. Vários autores estudam a ocorrência destas duas espécies de forma associada, devido à estreita proximidade entre as espécies, intitulando-as desta forma como complexo MAIS - Mycobacterium avium, $M$. intracellulare e $M$. scrofulaceum. Assim, as sete amostras de micobactérias de crescimento rápido isoladas no presente estudo pertencem ao complexo MAIS. Não foram isoladas nestes animais espécimes de Mycobacterium tuberculosis, Mycobacterium bovis, $M$. africanum ou $M$. microtii, consideradas como micobactérias típicas, ou pertencentes ao complexo M. tuberculosis.
Isolamentos de micobactérias do complexo MAIS e de crescimento rápido têm sido freqüentes em suínos sem lesões visíveis. Gontijo Filho et al. (1974) examinaram 200 gânglios linfáticos de suínos e isolaram 79 amostras de micobactérias atípicas, com predominância das de crescimento rápido, sobretudo da espécie $M$. fortuitum, e isolamento também de $M$. scrofulaceum e de amostras do complexo $M$. aviumintracellulare. Pestana de Castro et al. (1978), ao processarem 500 amostras de linfonodos mesentéricos sem lesão aparente de suínos dos estados de São Paulo e Paraná, isolaram 95 (19\%) amostras de micobactérias. A predominância foi de amostras do complexo MAIS, sem nenhum isolamento de $M$. bovis ou de $M$. tuberculosis.

Resultados similares foram verificados por Mota et al. (1980), que obtiveram maior proporção $(25,9 \%)$ de isolamentos de micobactérias de linfonodos macroscopicamente não lesados do que daqueles com lesões macroscópicas sugestivas de tuberculose, com predominância do complexo MAIS. Também Ferreira Neto et al. (1989) verificaram predominância do complexo $M$. avium-intracellulare em suínos abatidos em matadouros de São Paulo e observaram que o isolamento de amostras de $M$. bovis a partir de linfonodos de suínos, embora já tenha sido relatado, é considerado raro. Mais recentemente, Balian et al. (1997) relataram o predomínio de isolamento de micobactérias do complexo $M$. avium intracellulare $(93,4 \%)$ em suínos abatidos também no estado de São Paulo.

Segundo Bono et al. (1995), as amostras de MAC isoladas em pacientes humanos diferem bastante daquelas identificadas em aves. São, no entanto, bastante similares do ponto de vista genético àquelas isoladas de suínos. Desta forma, os autores sugerem que ambas as espécies estariam expostas a uma mesma exposição ambiental ou que suínos e produtos derivados destes estariam atuando como veículos de contaminação humana, e desta forma seu consumo pela população imunodeprimida representaria, assim, um sério risco sanitário. Estes dados são confirmados por Komijn et al. (1999), que isolaram amostras de MAC de origem suína e verificaram estreita similaridade genética com amostras de origem humana. Estes estudos sugerem forte inter-relação entre as amostras suínas e a contaminação humana por micobactérias do MAC.

Segundo Ferreira Neto et al. (1989), a técnica convencional de exame post-mortem baseada na lesão tuberculóide observada macroscopicamente, é um importante indicador de infecção micobacteriana em carcaças de suínos. Assim, a ação da fiscalização sanitária, ao identificar carcaças com lesões determinadas por micobactérias e condená-las para o consumo humano, consegue inibir a transmissão destes microrganismos para a população.

No presente estudo, 21 de 73 animais apresentaram crescimento de micobactérias a partir dos linfonodos examinados, o que representa $28,8 \%$ de isolamento. Ao considerarmos apenas as amostras de crescimento lento, que representam o complexo $M$. avium e a amostra de $M$. scrofulaceum isoladas, potencialmente mais patogênicas para o homem e animais, observamos isolamento destas em sete dos 73 animais testados, o que representa $9,6 \%$ de crescimento.

Dados acerca de animais de abate clandestino como vetores de micobacterioses são inexistentes em nosso meio. No en- 
tanto, consideramos os índices verificados bastante altos, especialmente tendo em vista que esses animais são consumidos diretamente sem qualquer espécie de fiscalização sanitária ou de tratamento sanitário prévio dos produtos. Desta forma, consideramos que os animais oriundos de abate clandestino representam importante risco de contaminação ambiental e da população humana exposta a micobactérias em geral e especialmente às do MAC.

\section{Agradecimentos}

Os autores agradecem o apoio do Prof. Zander B. Miranda (UFF), do CNPq e da FAPERJ.

\section{Referências}

ANDRADE, L.; KRITSKI, A.; OLIVEIRA, G.; SANTIAGO, A . Infecção pulmonar por Mycobacterium scrofulaceum. Jornal de Pneumologia, v. 12, n. 3, p. 175-179, 1986.

BALIAN,C.; RIBEIRO, P.; VASCONCELLOS, S.A.; PINHEIRO, S.R.; FERREIRA NETO, J.S.; GUERRA, J.L.; XAVIER, J.G.; MORAIS, Z.M.; TELLES, M.A.S. Linfadenites tuberculóides em suínos abatidos no Estado de São Paulo, Brasil: Aspectos macroscópicos, histopatológicos e pesquisa de micobactérias. Revista Saúde Pública, v. 31, n. 4, 1997.

BONO, M.; JEMMI, T.; BERNASCONI, C.; BURKI, D.; TELENTI, A.; BODMER, T. Genotypic characterization of Mycobacterium avium strains recovered from animals and their comparison to human strains. Applied and Environmental Microbiology, v. 61, n. 1, p. 371-373, 1995.

COMISSÃO ESPECIAL DE INSPEÇÃO HIGIÊNICA, SANITÁRIA E TECNOLÓGICADEPRODUTOSDEORIGEMANIMALNOESTADODO RIODE JANEIRO, DO CONSELHO REGIONALDEMEDICINA VETERINÁRIA - RJ. Relatório, 31 p., 1987.

FERREIRANETO, J.S.; CORTES, J.A.; SINHORINI, I.L; VASCONCELLOS, S.A.; ITO, F.H.; SILVA, E.A.M. A lesão tuberculóide macroscópica como critério diagnóstico da infecção micobacteriana em suínos abatidos em matadouro. Revista da Faculdade de Medicina Veterinária e Zootecnia da Universidade de São Paulo, v. 26, n. 1, p. 21-33, 1989.

FONSECA, L.S.; GONTIJO FILHO, P.P. Micobactérias atípicas isoladas de material humano na cidade do Rio de Janeiro. II. Identificação bioquímica e espectro de resistência aos tuberculostáticos. Revista de Microbiologia, v.;9, p.;149-155, 1978.

GONTIJO FILHO, P.P.; NASCIMENTO, D.; FONSECA, L.S. Isolamento de micobactérias atípicas a partir de gânglios linfáticos de suínos. Revista Microbiologia, v. 5, n. 3, p. 59-62, 1974.
HORSBURGH, C.R. M. avium complex infection in the acquired immunodeficiency syndrome. New England Journal of Medicine, $\mathrm{v}$. 324, p. 1332, 1991.

KENT, P.T.; KUBICA, G.P. Public health mycobacteriology. a guide for the level III laboratory. Atlanta: Center of Diseases Control 1985, $202 \mathrm{p}$.

KOMIJN, R.E.; HAAS, P.E.W.; SCHNEIDER, M.M.E.; EGER, T.; NIEUWENHUIJS, J.H.M.; HOEK, R.J.; BAKKER, D.; ERVELD, F.G.Z.; SOOLINGEN, D. Prevalence of Mycobacterium avium in slaughter pigs in the Netherlands and comparison of IS 1245 restriction fragment lenght polymorphism patterns of porcine and human isolates. Journal of Clinical Microbiology, v. 37, n. 5, p. 1254-1259, 1999.

MOTA, P.M.P.C.; LANGENEGGER, C.H.; LEITE, R.C.; LANGENEGGER, J. Micobactérias isoladas de suínos do Estado de Minas Gerais. Revista Microbiologia, v. 11, n. 1, p. 29-33, 1980.

PESTANA DE CASTRO, A .F.; CAMPEDELLI FILHO, O.; WAISBICH, E. Opportunist mycobacteria isolated from the mesenteric lymph nodes of apparently healthy pigs in São Paulo, Brazil. Revista Microbiologia, v. 9, n. 2, p. 74-83, 1978

PALHANO JR., L.; ANDRADE, L.; FONSECA, L.S. Mycobacterium fortuitum - avaliação bacteriológica de amostras isoladas no Rio de Janeiro. Jornal de Pneumologia, v. 12, n. 3, p. 170-174, 1986.

SAAD, M.H.F.; FONSECA, L.S.; FERRAZOLI, L.; FANDINHO, F.; PALACI, M.; GRINZTEJN, B.; KRITSKI, A.; WERNECK, A.; POLTORATSKAIA, N.; JOHNSONJR., W.D.; RILEY, L.W. IS1245 genotypic analysis of Mycobacterium avium isolates from patients in Brazil. International Journal of Infectious Diseases, v. 3, p. 192-196, 1999.

THOEN, C.O. Mycobacterium aviuminfections in animals. Research in Microbiology, v. 145, n. 3, p.173-177, 1994. 